IRA-International Journal of Education \&

Multidisciplinary Studies

ISSN 2455-2526; Vol.03, Issue 03 (2016)

Institute of Research Advances

http://research-advances.org/index.php/IJEMS

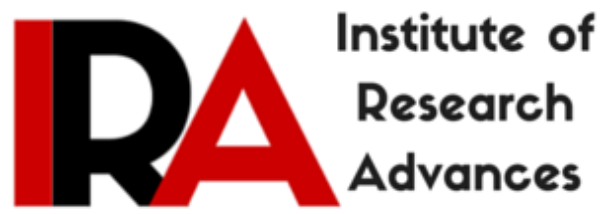

\title{
Competency Based Education and Training: A Fresh Green Leaf from the Australian Context for TVET in Africa
}

Makworo Edwin Obwoge

KISII University,

P. O Box 408-40200, KISII, Kenya.

DOI: http://dx.doi.org/10.21013/jems.v3.n3.p23

\section{How to cite this paper:}

Edwin Obwoge, M. (2016). Competency Based Education and Training: A Fresh Green Leaf from the Australian Context for TVET in Africa. IRA International Journal of Education and Multidisciplinary Studies (ISSN 2455-2526), 3(3). doi:http://dx.doi.org/10.21013/jems.v3.n3.p23

(C) Institute of Research Advances

\section{(c) EY-NC}

This works is licensed under a Creative Commons Attribution-Non Commercial 4.0 International License subject to proper citation to the publication source of the work.

Disclaimer: The scholarly papers as reviewed and published by the Institute of Research Advances (IRA) are the views and opinions of their respective authors and are not the views or opinions of the IRA. The IRA disclaims of any harm or loss caused due to the published content to any party. 


\begin{abstract}
The labour market in most developing countries in Africa has experienced challenges of qualified human resource to carry out their desired functions. The academic institutions are supposed to produce graduates who would readily fit into the job market. The TVET institutions were designed to produce graduates with technical skills to work in the industrial sector and other sectors of the economy in order to accelerate economic development. However there have been many complaints from many employers on noncompetence of most TVET graduates and this has seriously incapacitated economic development in Africa. Many employers have to spend time retraining the TVET graduates which wastes time and resources that would have been used in production. This paper reviews literature on competence based education and training and draws important lessons for application, policy formulation and improvement in the African systems. Competency-based education could serve as a game changer in Technical and Vocational Education, delivering high-quality education experiences that lead to demonstrated learning and mastery at an affordable price.
\end{abstract}

Key words: Competence Based Training, TVET, Technical skills

\title{
INTRODUCTION
}

Competency-based education has become a major topic of discussion in many education systems in the world today. This is because many employers are questioning qualifications awarded by training institutions since many graduates come out half-baked and can little handle the demands of the workplace set-up. It is becoming an increasingly popular concept as many institutions search for ways to improve college affordability and more accurately measure student learning. Competency-based education allows students to study and learn at their own pace. They can move quickly through material they already know and focus on what they still need to learn hence saving both time and money. Implemented effectively, competency-based education can improve quality and consistency, reduce costs, shorten the time required to graduate, and provide us with true measures of student learning. This is especially important because the learning outcome is the same for all abilities of learners and only time varies.

According to Soares, L (2012), the benefits of competency-based approach have been recognized by policy makers and influencers in higher education. The Center for American Progress recently released a white paper that found that competency-based education could be the key to providing quality postsecondary education to millions of Americans at lower cost. This gives a lot of hope and opportunity for investment for developing countries in Africa since financing education is a big challenge.

Most technical institutions require a lot of capital investment in order to be able to provide the services they require to their clients. This is due to lack of enough funds for investment in laboratory equipment and other learning resources. In most countries that have adopted competency based education, some learning resources are shared between industry and the training institutions hence cutting down on cost. 


\section{DEFINING COMPETENCY BASED TRAINING}

According to the Australian Vocational Education, Employment and Training Advisory Committee competence based training is training geared towards the attainment and demonstration of skills to meet industry-specified standards rather than to an individual's achievement relative to that of others in a group.

In Australia, the former National Training Board (NTB) developed a broad definition of competency which incorporated underpinning knowledge as well as values and attitudes. Key competencies were also developed to detail the necessary skills and attributes all young people should have on entering the workforce. They were to be incorporated into education and training programs operating in sectors other than the VET sector, that is, the secondary and higher education sectors. These competencies are:

- Collecting and analyzing information

- Communicating ideas and information

- Planning and organizing activities

- Working with others in teams

- Using mathematical ideas and techniques

- Solving problems

- Using technology

According to Smith and Keating (1997), CBT has the following characteristics;

- It's based on competency standards

- It focusses on outcomes not inputs

- It involves industry

- It takes account of recognition of prior learning (RPL)

- It's modularized

- It's self-paced

- It's assessment is based on demonstration of skills rather than knowledge

- It's assessment criterion-referenced and ungraded

- It has flexible delivery

- The competencies attained are widely recognized

The most important characteristic of competency-based education is that it measures learning rather than time. Students' progress by demonstrating their competence, which means they prove that they have mastered the knowledge and skills (called competencies) required for a particular course, regardless of how long it takes. While more traditional models can and often do measure competency, they are time-based. whereas most colleges and universities hold time requirements constant and let learning vary, competency-based learning allows us to hold learning constant and let time vary. It also changes the faculty role. Competency-based learning shifts the role of the faculty from that of "a sage on the stage" to a "guide on the side." Faculty members work with students, guiding learning, answering questions, leading discussions, and helping students synthesize and apply knowledge.

Competency-based education is an outcomes-based approach to education where the emphasis is on what comes out of the education system, that is, what graduates know and can do rather than what goes into the curriculum. With a competency-based approach, 
you do not begin preparing a course syllabus by identifying content and readings. Instead, you begin by identifying competencies and then select the content, readings, and assignments to support student attainment of those competencies.

In competency-based education, assessment is embedded in every step of the learning process in order to provide students with guidance and support toward mastery. This heightened level of assessment is designed to build competencies in real time. The following figure, from the National Postsecondary Education Cooperative's report "Defining and Assessing Learning," provides a simple yet powerful visual of the competency-based approach.

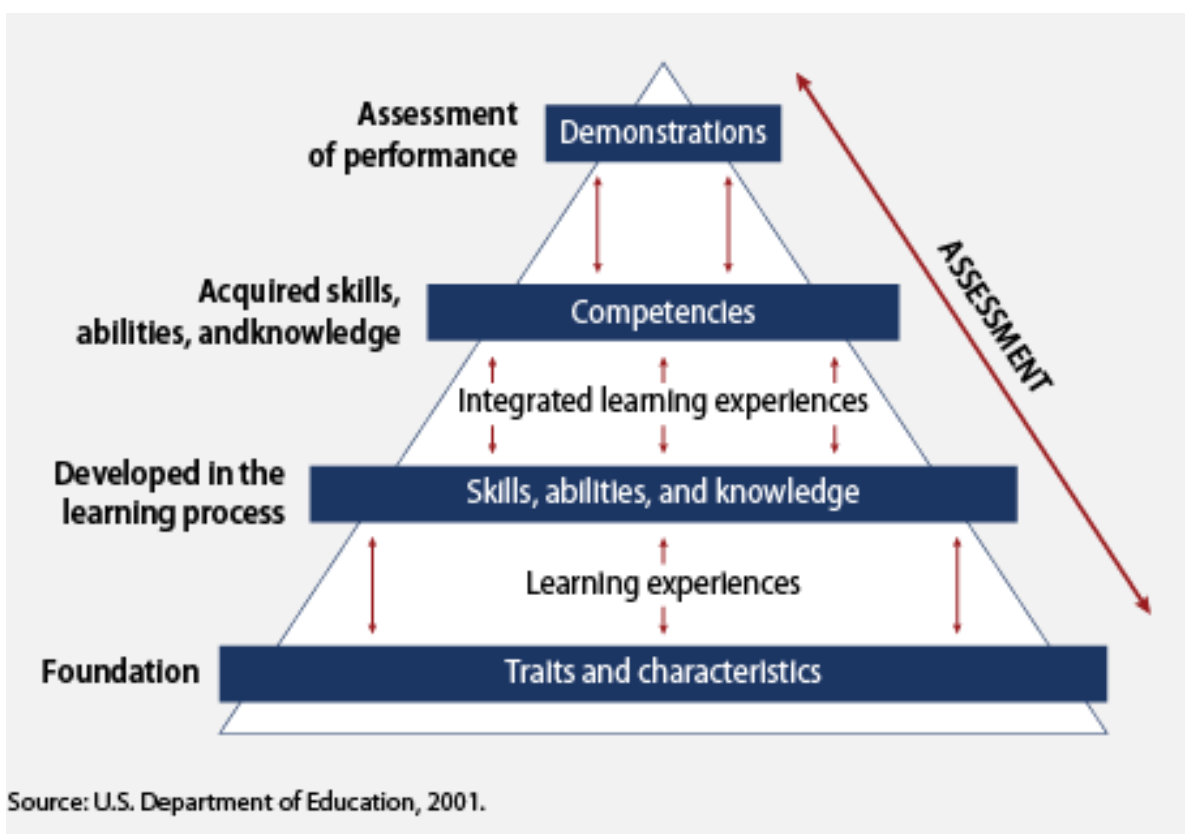

Considering the pyramid, at the lowest level are traits and characteristics which are the foundation of learning and depict the innate makeup of individuals upon which further experiences can be built. This are the great contributors towards different learner abilities. The second level consists of skills, abilities, and knowledge developed through learning experiences broadly defined to include formal education, work, and participation in community affairs. This are more general and cut across all fields of learning. The third level, competencies, are the outcome of integrated learning experiences, in which skills, abilities, and knowledge are focused on the performance of a task. The tasks are specific to a particular trade or area of study. Finally, the top-most level, demonstrations, results from the application of competencies. Assessment is deeply embedded at all stages of this learning process. The assessment moves from general skills to specific competencies attained up the pyramid.

It can be seen that the design of the learning experience is dependent upon standardized and agreed-upon definitions for skills, abilities, and knowledge; competencies; and demonstrations. Once students, faculty, employers, and policymakers agree upon competencies that must be mastered, avenues are opened for students to personalize their 
learning options by selecting among different providers. They are free to go for providers whose instructions are delivered at the lowest cost but with same mastery of a subject.

Smith et al. (1996), in their study of the availability of competency-based training in TAFE and non-TAFE institutions in Australia showed that in 1994 the impact of CBT implementation was neither extensive nor comprehensive. This indicates that attaining a well-organized CBT system takes time and effort. They found that the proportion of CBT courses in TAFE had grown from 13 per cent in 1990 to 29 per cent in 1994. This is a small growth over 4 year period. Lowrie et al. (1999) conducted a nation-wide survey of teachers/trainers, as well as six case studies of CBT delivery, to examine the effects of CBT on the role of teachers/trainers in both TAFE and private providers of TVET. They found that over two thirds of teachers/trainers surveyed were strongly positive about CBT and that over 80 per cent of them considered they had a thorough understanding of CBT. This are several years after the start of CBT in Australia and this suggests that CBT had now been in place for long enough for practitioners to have developed a satisfactory understanding of its process and structure. This clearly indicates that developing countries in Africa must be patient enough before they can see the fruits of CBT.

Foster (1998) conducted a study of CBT implementation in Victoria and found strong industry support for CBT, particularly for training based on industry-defined competency standards and that which recognized the role of the workplace in training. The Industrial sector is often enticed when they realize what is in the project for them. It's therefore important to work together with industry in defining competencies. Foster (1998) also found that CBT was well established in industry sectors such as building and construction, food, engineering, tourism and hospitality, and some areas of community services and health, such as child care, but only recently established in other sectors, such as agriculture, and yet to be implemented in most other areas of community services. It therefore apparent that sectors that have fast demanded service delivery are likely to be more positive and responsive to introduction of CBT in developing countries.

\section{BENEFITS OF COMPETENCY BASED TRAINING}

Mulcahy and James (1999) examined in detail the impact of CBT on Australian enterprises and found that CBT provided for the achievement of the following outcomes:

- Specific, predominantly technical skill but was less effective in providing broadbased attitudinal/behavioural skills

- Skills specific to individual enterprises many of which combined national competency standards with enterprise standards

- Procedural knowledge and capacities for routine problem-solving but conceptual, tacit and experiential knowledge were given less attention

- Ability to handle frequently recurring routine tasks but the ability to use existing knowledge in new ways and new solutions was given less attention

Mulcahy and James (1999) also found that CBT benefitted particular stakeholders in the following ways: 
Employers: The main benefits of CBT to employers are that;

- Learning can be achieved on the job.

- Competencies can be developed which are suited to immediate needs (as well as leading to a recognized qualification for employees).

- Employers can set standards (e.g. in-house competencies) and use standards already set (e.g. national competencies).

Supervisors: The benefits of CBT to supervisors are that;

- It provides greater transparency in training through presenting clear information on outcomes, thus lessening the need for supervision.

- The synergy between training outcomes and other desired outcomes like quality and safety has distinct advantages in the context of supervision.

Students and trainees: The main benefits for students of CBT are;

- Gaining recognition of their skills and formalizing this recognition through national qualifications.

- Opportunity to apply learning directly to the workplace and achieve 'real' results.

Billett et al (1999) also found enterprises had positive attitudes to the introduction of CBT and reported that multi-skilling, student competence and relevance of courses had all been enhanced by CBT. Closer interaction with enterprises has led to outcomes appreciated by both industry and students. The studies also suggest CBT has been very successful in linking more directly the worlds of work and vocational education and training. Developing countries in Africa need to borrow a leaf on this from the Australian context.

Smith (1997) conducted studies on the impact of CBT on teachers and all agreed that their role had changed with the implementation of CBT. These specific changes to the teacher/trainer role were:

- An equalization of the relationship between teacher and student

- Becoming more aware of the needs of individual students

- Changing work organization to include more teamwork and in some cases the introduction of new lower-level teaching positions

- An increase in administrative duties

- Tailoring learning materials to meet the needs of local industry

- Writing learning guides to augment CBT modules

The TVET trainers in developing countries in Africa should hence be flexible to accommodate changes they will likely face in their work environment.

\section{THE CHALLENGE OF TVET TRAINING IN AFRICA}

According to Nyankov (1996), TVET in developing countries has the following c summarised these concerns challenges;

- Poor quality in the delivery of TVET programmes;

- High cost of training;

- Training not suited to actual socio-economic conditions;

- Disregard of the needs of the informal sector; and

- Disregard of the labour market and high unemployment rate among graduates 
In an attempt to address these challenges, Reddan and Harrison (2010) argued that TVET institutions need to restructure their programmes to be responsive to the needs of the job market, especially the industry. To achieve this goal, TVET curricula must focus on outcomes in terms of the skills, knowledge and attitudes required industry. That is, TVET provision should be responsive to the demands of industry. Only competency based training can be able to achieve this.

If more attention to key competencies and partnerships between TVET institutions and workplace is enhanced extended learning will take place and specific, job-related skills and general vocational education requirements will be met by TVET in developing countries in Africa.

\section{CONCLUSIONS}

Most African countries TVET systems have immense challenges ranging from financing, policy and even good will from the stakeholders. Competency based education is the real road towards development in Africa. Some countries have embraced CBT at its very initial stages but while policy makers are praising competency-based education, not enough is being done to ensure that our rules and regulations support it. For example, financial aid rules are generally based on seat time, and accreditation requirements tend to focus on reviews of faculty credentials, course materials, and time measures rather than what students are learning. Moving competency-based education into the mainstream will require a fundamental change in the way we look at higher education in Africa, but the improvements we will gain in student learning, efficiency, and affordability will be worth it.

\section{RECOMMENDATIONS}

Based on the above challenges facing TVET systems in the African continent, the following recommendations can help inform policy and go a long way in trying to improve these systems in Africa;

1. The developing countries in African should be dynamic and swift in incorporating current workplace changes within their TVET institutions and curriculum in order to be responsive to the needs of the job market.

2. Industry TVET training councils should be set up in order to enhance linkages between the two institutions for better graduate employability outcomes.

3. The TVET systems in Africa should harness the power of technology for teaching and learning. Computer-mediated instruction allows the ability to individualize learning for each student. Because each student learns at a different pace and comes to college knowing different things. This is a fundamental requirement of competency-based education.

4. The developing countries that have not embraced competency standards should consider developing them in collaboration with industry in order to ensure that they capture their specific needs and beyond.

5. Developing countries in Africa should ensure that they have National Qualification Frameworks that are very important in developing competency standards and defining the levels applicable to the standards.

6. Staff development to support the introduction of CBT for teachers and trainers should be planned for inadequately and continuing needs for professional 
development be fully met. This will be a key factor in the success of developing countries in Africa.

\section{REFERENCES}

Billett, S., McKavanagh, C., Beven, F., Hayes, S., Angus, L., Seddon, T., Gough, J. \& Robertson, I. (1999). The CBT decade: Teaching for flexibility and adaptability. NCVER; Adelaide.

Foster, S. (1998). CBT in Victoria. Office of Training and Further Education; Melbourne.

Lowrie, T., Smith, E. \& Hill, D. (1999). Evaluation of the contribution that competency based approaches have had on the role of instructors. NCVER; Adelaide.

Mulcahy, D. \& James, P. (1999). Evaluating the contribution of competency-based training. NCVER; Adelaide.

Nyankov, A. (1996) Current issues and trends in technical and vocational education. Paris, France: UNEVOC-International Project on Technical and Vocational Education.

Reddan, G., \& Harrison, G. (2010). Restructuring the bachelor of exercise science degree to meet industry needs. Asia-Pacific Journal of Cooperative Education, 11(1), 13-25.

Smith, E., Hill, D., Smith, A., Perry, P., Roberts, P. \& Bush, A. (1996). The availability of competency-based training in TAFE and non-TAFE settings in 1994. AGPS; Canberra.

Smith, E \& Keating, J. (1997). Making sense of training reform and competency-based training. Social Science Press: Wentworth Falls.

Soares, L (2012): A 'Disruptive' Look at Competency-Based Education: How the Innovative Use of Technology Will Transform the College Experience. Centre for American Progress. 